\title{
Myocardial ischaemia and ventricular arrhythmias precipitated by physiological concentrations of adrenaline in patients with coronary heart disease
}

\author{
Alastair J McCance, J Colin Forfar
}

\begin{abstract}
The clinical and haemodynamic effects of adrenaline infusion (30 $\left.\mathrm{g} \mathrm{kg}^{-1} \mathrm{~min}^{-1}\right)$ producing plasma adrenaline concentrations in the range seen during acute myocardial infarction and of placebo were investigated in a crossover design in 14 patients with stable coronary heart disease. Adrenaline infusion resulted in electrocardiographic evidence of myocardial ischaemia ( $\geq 1 \mathrm{~mm}(0.1 \mathrm{mV})$ horizontal or downsloping ST segment depression) in 10 patients and angina in four, although the mean (SEM) increase in heart rate was modest (14 (2) beats/ min) and mean coronary vascular resistance fell from $1.56(0.21)$ to 1.16 $(0.14) \mathrm{mm} \mathrm{Hg} \mathrm{min} \mathrm{ml}^{-1}$ (p < 0.005). New or increasingly frequent or complex ventricular arrhythmias occurred in five patients. Placebo infusion had no effect on the variables measured. Supine bicycle exercise during infusion of the saline placebo was associated with a similar degree of ST segment depression (0.9 $(0.2) \mathrm{mm}$ ) as adrenaline infusion at rest $(0.9(0.1) \mathrm{mm})$ but exercise performed during adrenaline infusion (10 patients) resulted in more pronounced ST segment depression (1.9 (0.3) $\mathrm{mm})$ $(p<0.005)$ than either intervention alone. Angina occurred in three of 11 patients during control exercise and in six of 10 during the combination of adrenaline infusion and exercise.

Such potentially adverse consequences of low dose adrenaline infusion in patients with stable coronary heart disease are consistent with the suggestion that adrenal activation is detrimental during acute myocardial infarction, being both arrhythmogenic and proischaemic.
\end{abstract}

Department of Cardiovascular Medicine, John Radcliffe Hospital, Oxford

A J McCance

J C Forfar

Correspondence to

Dr Alastair J McCance,

Department of Cardiology,

Groby Road Hospital,

Leicester LE3 9QE.

Accepted for publication 23 May 1991
Acute myocardial infarction is associated with sympathoadrenal activation, and plasma adrenaline concentrations can reach 100 times the baseline upper limit of normal. ${ }^{1}$ Karlsberg et al found that a high peak adrenaline concentration was associated with increased subsequent mortality, ${ }^{1}$ but it is not clear whether this adverse outcome is due to the high adrenaline concentrations or whether high concentrations are a marker for large infarcts and associated with a poor prognosis for that reason. Nevertheless, the concept that adrenal activation may have significantly adverse consequences after acute myocardial infarction has received little recent attention. The aim of the present study was to investigate whether brief low dose adrenaline infusions, designed to simulate the increases in adrenaline concentration seen during acute myocardial infarction, result in myocardial ischaemia or ventricular arrhythmias in patients with stable symptomatic coronary heart disease.

\section{Patients and methods}

PATIENTS

Fourteen male patients, whose clinical details are shown in the table, were studied supine and in the fasting state one hour after diagnostic cardiac catheterisation. All had coronary heart disease ( $>50 \%$ diameter stenosis of at least one major coronary artery), all had a history of stable typical angina, and six had had a previous myocardial infarction. Thirteen had had a diagnostic treadmill exercise test (Bruce protocol) at least one week before catheterisation. Chronic oral medication was stopped the day before study and $\beta$ adrenoceptor antagonists were stopped at least 72 hours before. The resting left ventricular ejection fraction was determined from the right anterior oblique cineangiogram. ${ }^{2}$ All subjects gave informed consent to the study, which was approved by the Central Oxford Research Ethics Committee.

METHODS

After left ventricular and coronary angiography, performed by the standard femoral approach, a Baim coronary sinus flow catheter (Electro-catheter Corporation, New Jersey) was inserted via the right subclavian vein. Correct placement in the distal coronary sinus was confirmed by injection of a small quantity of contrast material. This permitted repeated measurement of coronary sinus blood flow by thermodilution, as we have previously described. $^{3}$

After insertion of the Baim catheter, patients were transferred to the research laboratory. Adrenaline $(250 \mu \mathrm{g})$ was diluted to $50 \mathrm{ml}$ in saline $(154 \mathrm{mmol} / 1 \mathrm{NaCl})$. Adrenaline (30 $\mathrm{ng} \mathrm{kg}^{-1} \mathrm{~min}^{-1}$ ) and matching saline placebo were infused double blind and in 
Clinical data on 14 study patients with coronary heart disease

\begin{tabular}{|c|c|c|c|c|c|c|}
\hline Case & $\begin{array}{l}\text { Age } \\
(y)\end{array}$ & $\begin{array}{l}\text { LVEF } \\
(\%)\end{array}$ & $\begin{array}{l}B P \\
(m m H g)\end{array}$ & $C A D$ & Drugs & $\begin{array}{l}\text { Diagnostic ETT (Bruce } \\
\text { stage/degree and site of } S T \text { ) }\end{array}$ \\
\hline $\begin{array}{l}1 \\
2 \\
3 \\
4 \\
5 \\
6\end{array}$ & $\begin{array}{l}55 \\
40 \\
64 \\
58 \\
58 \\
61\end{array}$ & $\begin{array}{l}47 \\
55 \\
75 \\
59 \\
68 \\
83\end{array}$ & $\begin{array}{l}135 / 87 \\
157 / 92 \\
141 / 78 \\
171 / 90 \\
190 / 101 \\
160 / 90\end{array}$ & $\begin{array}{l}\text { LAD, Cx, RCA } \\
\text { Cx } \\
\text { LAD, Cx, RCA } \\
\text { RCA } \\
\text { LAD, Cx } \\
\text { LM, LAD, Cx, } \\
\text { RCA }\end{array}$ & $\begin{array}{l}\text { At, asp, nif, ISDN, ranit } \\
\text { At, asp, ISDN } \\
\text { At, asp, dilt, ISDN } \\
\text { At, dilt, ISDN } \\
\text { At, asp, dilt, ISDN } \\
\text { At, asp, ISDN }\end{array}$ & $\begin{array}{l}2 / \text { none } \\
2 / 2.5 \mathrm{~mm} / \text { lat } \\
2 / 2 \mathrm{~mm} / \text { ant-lat } \\
2 / \text { none } \\
2 / 1 \mathrm{~mm} / \text { inf-lat } \\
4 / 1 \mathrm{~mm} / \text { lat }\end{array}$ \\
\hline $\begin{array}{l}7 \\
8 \\
9 \\
10 \\
11 \\
12 \\
13 \\
14 \\
\text { Mean (SEM) }\end{array}$ & $\begin{array}{l}46 \\
58 \\
59 \\
67 \\
55 \\
50 \\
44 \\
61 \\
55(2)\end{array}$ & $\begin{array}{l}58 \\
79 \\
74 \\
62 \\
61 \\
78 \\
64 \\
63 \\
66(3)\end{array}$ & $\begin{array}{l}108 / 63 \\
149 / 93 \\
137 / 77 \\
164 / 94 \\
137 / 82 \\
132 / 92 \\
105 / 73 \\
172 / 101 \\
147 / 87(6 / 3)\end{array}$ & $\begin{array}{l}\text { RCA } \\
\text { LAD, Cx, RCA } \\
\text { Cx } \\
\text { RCA } \\
\text { LAD, Cx } \\
\text { LAD, Cx, RCA } \\
\text { Cx } \\
\text { Cx, RCA }\end{array}$ & $\begin{array}{l}\text { At, asp, cimetidine } \\
\text { At, GTN } \\
\text { At, asp } \\
\text { At, asp } \\
\text { Tim, asp, nif, ISDN } \\
\text { Met, asp, bezafibrate } \\
\text { At, asp } \\
\text { Bisop, asp, ISDN }\end{array}$ & $\begin{array}{l}3 / 1 \mathrm{~mm} / \text { lat } \\
3 / 1 \mathrm{~mm} / \text { lat } \\
2 / 0.5 \mathrm{~mm} / \text { lat } \\
2 / 1.5 \mathrm{~mm} / \text { inf-lat } \\
2 / 3 \mathrm{~mm} / \text { lat } \\
2 / \text { none } \\
2 / 2.5 \mathrm{~mm} / \text { lat }\end{array}$ \\
\hline
\end{tabular}

Ant-lat, anterolateral; Asp, aspirin, at, atenolol; bisop, bisoprolol; BP, blood pressure; CAD, coronary artery disease; Cx, circumflex coronary artery; dilt, diltiazem; ETT, exercise tolerance test; GTN, long acting glyceryl trinitrate; inf-lat, inferolateral ISDN, isosorbide dinitrate; LAD, left anterior descending coronary artery; lat, lateral; LM, left main coronary artery; LVEF, left ventricular ejection fraction; met, metoprolol; nif, nifedipine; ranit, ranitidine; RCA, right coronary artery; ST, ST segment depression; tim, timolol.

random order into a peripheral vein, each for 30 minutes. Eleven patients performed supine bicycle exercise using the left leg during the final 10 minutes of the first infusion. During the first minute of exercise the load on an electrically braked bicycle (Elema-Schönander AM 368, Sweden) was adjusted to a comfortable level and exercise was continued for 10 minutes. Exercise and the first infusion were then stopped and the patients rested supine for 10 minutes before the second infusion was started. Ten subjects repeated an identical exercise protocol during the final 10 minutes of the second infusion. Coronary sinus blood flow was measured in duplicate and standard 12 lead electrocardiograms were recorded at rest and during exercise during each infusion. The arterial blood pressure was measured every three minutes during the protocol by an automatic blood pressure recorder (Copal Digital Sphygmomanometer, UA 251) and three electrocardiographic leads were monitored continuously and recorded on magnetic tape. Adrenaline concentrations were measured by high performance liquid chromatography with electrochemical detection, as we have previously described. ${ }^{4}$

\section{STATISTICAL ANALYSIS}

The responses of the ST segment, blood pressure, heart rate, and rate-pressure product to exercise during saline and adrenaline infusion were compared by two way analysis of variance. Coronary vascular resistance and coronary blood flow during saline and adrenaline infusion were compared by a two tailed paired $t$ test. All results are expressed as mean (SEM). Results were taken to be statistically significant at the $5 \%$ level.

\section{Results}

Adrenaline infusion increased the heart rate $(81$ (2) $v 67(3)$ beats $/ \mathrm{min}, \mathrm{p}<0.001$ ) and tended to increase systolic blood pressure (146 (6) $\mathrm{mm} \mathrm{Hg} v 141(7), \mathrm{p}<0.15)$ and to decrease diastolic blood pressure $(79$ (4) $v$ 82 (3) $\mathrm{mm} \mathrm{Hg}, \mathrm{p}<0.1)$. Adrenaline had no effect on mean arterial pressure (100 (4) $v 102$
(4) $\mathrm{mm} \mathrm{Hg}$ ). Coronary sinus blood flow increased during adrenaline infusion (109 (18) $v 90(18) \mathrm{ml} / \mathrm{min}(\mathrm{p}<0.001)$ and there was a corresponding fall in coronary vascular resistance $(1.16(0.14) v 1.56(0.21) \mathrm{mm} \mathrm{Hg} \mathrm{min} /$ $\mathrm{ml}, \mathrm{p}<0.005)$ (fig 1). There was no significant difference in any of the measured variables between infusion 1 and infusion 2 and thus no evidence of an order effect of the adrenaline and saline infusions. The mean exercise load achieved by the 11 patients who exercised was 26 (3) W.

During adrenaline infusion arterial and venous adrenaline concentrations increased from $0.37(0.05) \mathrm{nmol} / 1$ to $3.09 \quad(0.24) \mathrm{nmol} / 1$ $(\mathrm{p}<0.001)$ and from $0.31(0.04) \mathrm{nmol} / \mathrm{l}$ to $1.64(0.19) \mathrm{nmol} / 1$ respectively $(\mathrm{p}<0.001)$. No patient had significant ST segment depression at rest or during saline infusion. Ten of the 14 patients developed clear electrocardiographic evidence of myocardial ischaemia ( $\geq 1 \mathrm{~mm}(0 \cdot 1 \mathrm{mV})$ horizontal or downsloping ST segment depression $80 \mathrm{~ms}$ after the J point) during adrenaline infusion, which was symptomatic in four, and one patient developed asymptomatic ST segment depression of $<1 \mathrm{~mm}$. Supine bicycle exercise resulted in electrocardiographic evidence of ischaemia in seven of 11 patients during saline infusion and ST segment depression of $<1 \mathrm{~mm}$ in one patient. Angina developed during exercise in four patients. The degree of ST segment depression was similar at rest during adrenaline infusion and during the control exercise period $(0.9(0.1) \mathrm{mm}$ and $0.9(0.2) \mathrm{mm}$ respectively) Exercise during the adrenaline infusion was associated with $\geq 1 \mathrm{~mm}$ of ST segment depression in eight of 10 patients, and with angina in seven of these. The degree of ST segment depression $(1.8(0.3) \mathrm{mm})$ was significantly greater than during the control exercise period $(p<0.005)$ (fig 2). Figure 3 shows representative electrocardiograms from a patient (case 6).

Exercise produced a greater increase in heart rate than adrenaline infusion ( 22 (3) beats $/ \mathrm{min}$ $v 14(2)$ beats $/ \mathrm{min}, \mathrm{p}<0.01)$ and the increases in heart rate were similar during the control 
Figure 1 Thermodilution coronary sinus blood flow, mean arterial pressure, and calculated coronary vascular resistance during saline and adrenaline infusion ( $30 \mathrm{ng} \mathrm{kg}^{-1} \mathrm{~min}^{-1}$ ) in 14 patients with coronary heart disease.
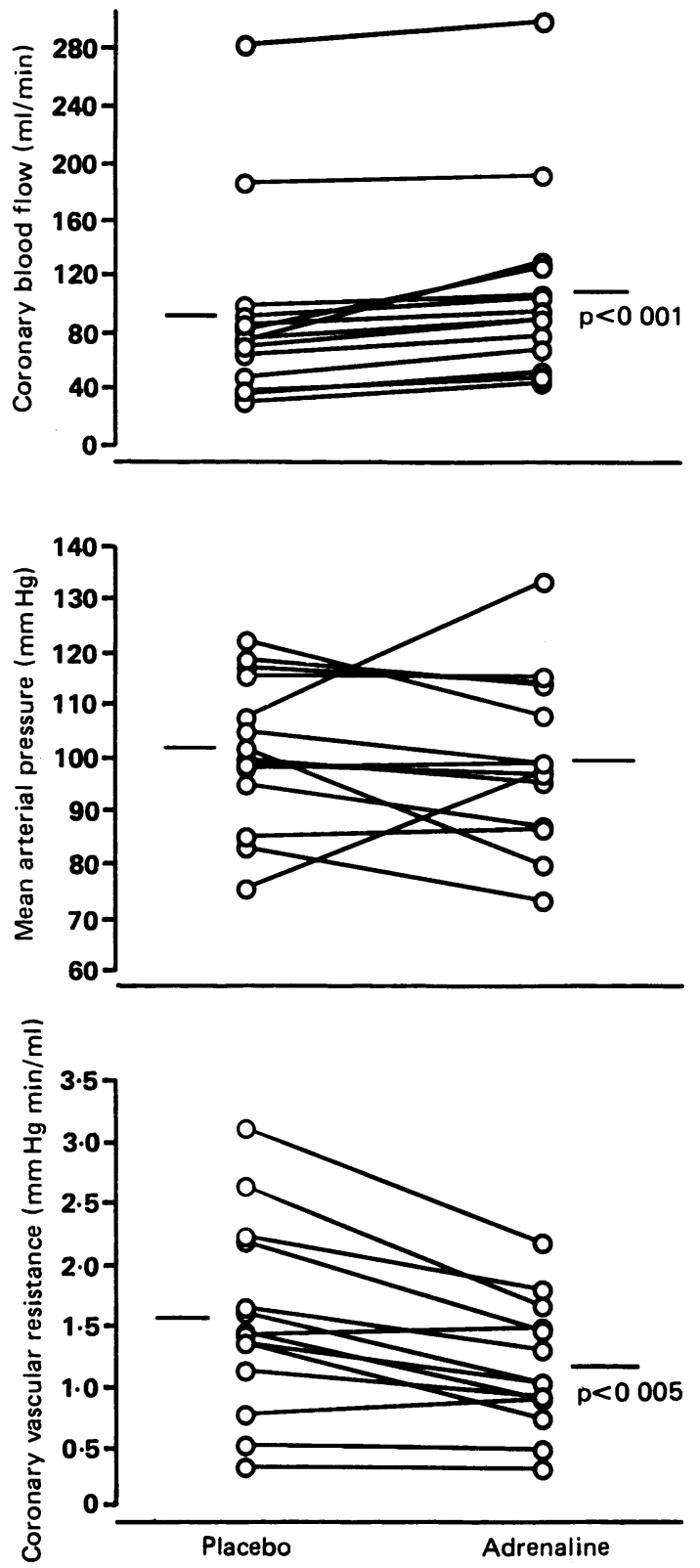

and adrenaline exercise periods (22 (3) beats/ $\min v 20$ (3) beats/min). The rate-pressure product $\left(9493(811) \mathrm{mm} \mathrm{Hg}\right.$. beats $\mathrm{min}^{-1}$ at rest during placebo) increased during adrenaline infusion and during both exercise periods, but was greater during the control exercise period (13857 (1784) $\mathrm{mm} \mathrm{Hg}$. beats $\mathrm{min}^{-1}$ ) than during adrenaline infusion at rest (11924 (671) $\mathrm{mm} \mathrm{Hg}$. beats min, $\mathrm{p}<0.01)$ and was greatest during adrenaline infusion and exercise $(16801$ (1100) $\mathrm{mm} \mathrm{Hg}$. beats $\mathrm{min}^{-1}, \mathrm{p}<0.01 v$ exercise placebo and rest adrenaline).

Ventricular arrhythmias occurred for the first time, or, if already present, became more frequent or more complex in five of 14 patients during adrenaline infusion. Two patients developed unifocal ventricular extrasystoles during the adrenaline exercise period, when none had been present at rest or during the control exercise period. One patient, who did not exercise, developed ventricular couplets during adrenaline infusion, infrequent multifocal ventricular extrasystoles having been

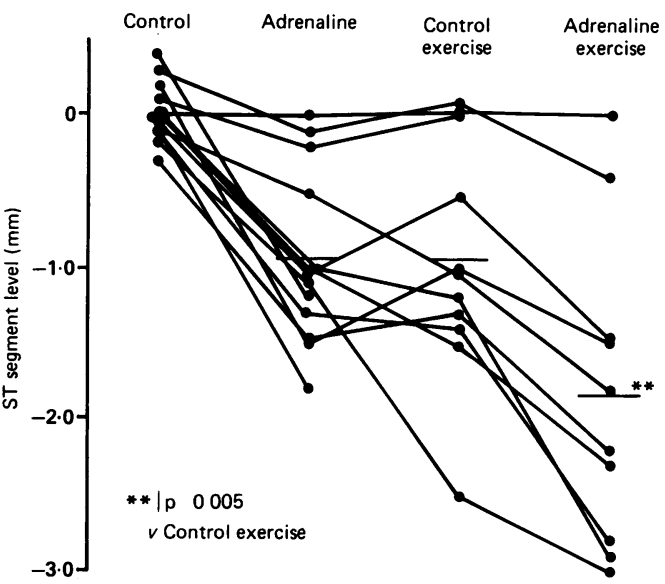

Figure 2 ST segment changes during adrenaline infusion, supine bicycle exercise during placebo infusion, and supine bicycle exercise during adrenaline infusion $(1 \mathrm{~mm}=0.1 \mathrm{mV})$. There was significant $S T$ segment depression during both adrenaline infusion and control exercise in most patients and the degree of ST segment depression was greatest during the adrenaline exercise period.

present during the saline infusion; one patient developed frequent ventricular extrasystoles, a brief period of ventricular bigeminy, and ventricular couplets during both control and adrenaline exercise periods; and one patient developed sustained ventricular bigeminy during adrenaline infusion, having had no arrhythmia at rest or during the control exercise period. No arrhythmia required specific treatment.

\section{Discussion}

In this study of patients with one, two, three, and four vessel coronary heart disease, infusion of adrenaline to produce physiological increases in plasma adrenaline concentration frequently resulted in myocardial ischaemia, which was often asymptomatic. Ventricular arrhythmias were also frequently precipitated

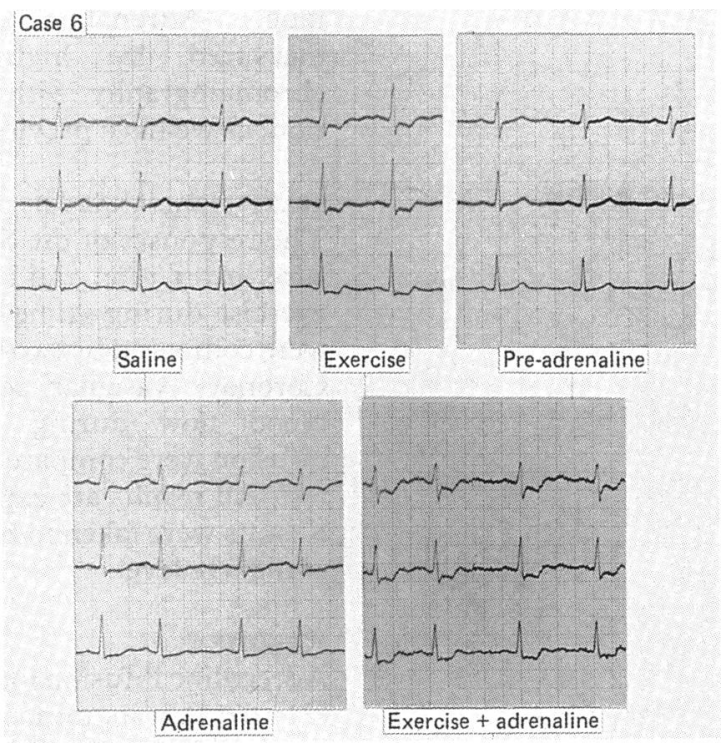

Figure 3 Electrocardiograms (leads V3, V5, V6) from a patient with coronary heart disease during infusion of saline placebo at rest and while exercising, after recovery from exercise (pre-adrenaline), and during adrenaline infusion at rest and while exercising. 
or exacerbated. The concentrations of adrenaline in this study, $1.64(0.19) \mathrm{nmol} / 1$ and 3.09 $(0.24) \mathrm{nmol} / \mathrm{l}$ in venous and arterial plasma respectively, are well within the range reported in patients with acute myocardial infarction. McAlpine et al reported admission venous adrenaline to be $3.54(1.30) \mathrm{nmol} / \mathrm{l}$ in patients with acute myocardial infarction and heart failure, ${ }^{5}$ while in patients with cardiogenic shock Benedict and Grahame-Smith reported a mean (SE) adrenaline concentration of $6 \cdot 17$ (1.04) $\mathrm{nmol} / \mathrm{1}^{6}$ and Karlsberg et al reported values as high as $37 \cdot 7 \mathrm{nmol} / 1 .^{1}$ The concentrations of adrenaline produced in this study are also reached during heavy physical exercise, when mean venous adrenaline concentrations of $2 \cdot 0-3.5 \mathrm{nmol} / 1$ have been reported. ${ }^{78} \mathrm{In}$ normal healthy controls these concentrations of adrenaline, whether the result of adrenaline infusion or exercise, are well tolerated, ${ }^{9}{ }^{10}$ but this is not the case in patients with coronary heart disease. The dose of adrenaline used in this study is approximately 30 times less than the dose used in anaphylactic shock or cardiac arrest.

The potential adverse effects of adrenaline in the setting of acute myocardial infarction are well recognised: the positive inotropic and chronotropic effects of $\beta$ adrenoceptor stimulation may compromise oxygen balance in critically underperfused myocardium, thus increasing infarct size ${ }^{11}$ and possibly the risk of myocardial rupture, and may cause distant myocardial ischaemia in patients with multivessel coronary disease (further compromising pump function and increasing the risk of arrhythmia): the direct arrhythmogenic effects and potential cardiotoxicity of catecholamines are well known. ${ }^{12}{ }^{13}$ Also of potential importance in view of the advent of thrombolytic therapy is the suggestion that catecholamines may be implicated in the genesis of reperfusion arrhythmias. $^{14}$

We cannot be certain whether the deleterious effects of adrenaline are catecholamine specific or are due to the increase in heart rate, but it seems unlikely that it is purely a heart rate effect. Adrenaline infusion caused myocardial ischaemia as severe as did supine bicycle exercise, although the heart rate and rate-pressure product were less during adrenaline infusion than during supine bicycle exercise. Although increased oxygen demand, of which the ratepressure product is an indicator, ${ }^{1516}$ was clearly a factor in producing ischaemia during adrenaline infusion, the lesser double product for a similar degree of ischaemia compared with dynamic exercise suggests that other mechanisms may also have been operating. One possibility is local coronary steal. It has been suggested that $\alpha$ mediated coronary vasoconstriction may help to maintain subendocardial flow during exercise. ${ }^{17}$ Humoral adrenaline, a potent $\beta_{2}$ as well as an $\alpha$ agonist, is likely to have been less active in this regard than neuronally secreted noradrenaline, and although coronary blood flow increased and total coronary vascular resistance fell during adrenaline infusion it is possible that coronary vasodilatation in normal segments, especially those distal to an organic stenosis, may have diverted flow away from the ischaemic subendocardium.

We showed that in patients with stable, symptomatic coronary heart disease infusion of low dose adrenaline to mimic the increases in adrenaline concentration seen during acute myocardial infarction commonly caused myocardial ischaemia and ventricular arrhythmias. Although the situation in acute myocardial infarction is manifestly not the same as in chronic stable ischaemic heart disease it is likely that adrenaline has similar and potentially important deleterious effects in acute infarction. The current study raises the possibility that adrenaline, in addition to having a direct arrhythmogenic effect, may promote ischaemia distant from the area of infarction without causing substantial changes in heart rate or blood pressure.

This work was supported by the British Heart Foundation. AJM was a Syntex research fellow. We acknowledge the expert technical assistance of Mr PA Thompson.

1 Karlsberg RP, Cryer PE, Roberts R. Serial plasma catecholamine response early in the course of acute myocardial infarction: relationship to infarct extent and mortality. $A m$ Heart J 1981;102:24-9.

2 Sandler H, Dodge HT. Angiographic methods for determination of left ventricular geometry and volume. In: Mirsky I, Ghista GN, Sandler H, eds. Cardiac mechanics: physiological, clinical and mathematical considerations. New York: John Wiley, 1974:141

3 McCance AJ, Forfar JC. Cardiac and whole body $\left[{ }^{3} \mathrm{H}\right]$ noradrenaline kinetics in ischaemic heart disease: contrast between unstable anginal syndromes and pacing induced ischaemia. $B r$ Heart $J$ 1989;61:238-47.

4 McCance AJ, Forfar JC. Cardiac and whole body $\left.{ }^{3} \mathrm{H}\right]$ noradrenaline kinetics during adrenaline infusion in man. Clin Sci 1991;80:227-33.

5 McAlpine HM, Morton JJ, Leckie B, Rumley A, Gillen G, Dargie HJ. Neuroendocrine activation after acute myocardial infarction. Br Heart $J$ 1988;60:117-24.

6 Benedict CR, Grahame-Smith DG. Plasma adrenaline and norangen concentrations and dopamine- $\beta$-hydroxynoradrenaline concentrations and dopamine- $\beta$-hydroxylase activity in myocardial infarction with and

7 Cryer PE. The physiology and pathophysiology of the human sympathoadrenal neuroendocrine system. $N$ Engl human sympathoadrenal

8 Halter JB, Stratton JR, Pfeifer MA. Plasma catecholamines and haemodynamic responses to stress states in man. Acto and haemodynamic responses to stress

9 Fellows IW, MacDonald IA, Bennet T, O'Donoghue DP. Effect of intravenous infusion of adrenaline on the cardiovascular responses to distal subatmospheric pressure in man. Clin Sci 1988;75:389-94.

10 Freyschuss U, Hjemdahl P, Juhlin-Dannfelt A, Linde B. Cardiovascular and metabolic responses to low dose adrenaline infusion: an invasive study in humans. Clin Sci 1986;70:199-206.

11 Herbaczynska-Cedro $\mathrm{K}$. The influence of adrenaline secretion on the enzymes in heart muscle after acute coronary occlusion in dogs. Cardiovasc Res 1970;4:168-75.

12 Corr PB, Witkowski FX, Sobel BE. Mechanisms contributing to malignant dysrhythmias induced by ischemia in the cat. $J$ Clin Invest 1978;61:109-19.

13 Rona G. Catecholamine cardiotoxicity. J Mol Cell Cardiol 1985;17:291-306.

14 Schwartz PJ, Zuanetti G. Role of the autonomic nervous system in reperfusion arrhythmias. $J \mathrm{Mol}$ Cell Cardiol 1988;20(suppl II):113-8.

15 Armbrecht JJ, Buxton DB, Brunken RC, Phelps ME, Schelbert HR. Regional myocardial oxygen consumption determined noninvasively in humans with 1-["C]acetate determined noninvasively in humans with $1-[$ "Cocetate and dynamic

16 Camici P, Marraccini P, Marzilli M, et al. Coronary hemodynamics and myocardial metabolism during and hemodynamics and myocardial metabolism during and after pacing stress
1989;257:E309-17.

17 Fiegl EO. The paradox of adrenergic coronary vasoconstriction. Circulation 1987;76:737-45. 